\title{
Family Practice is a Highly Complex Business
}

\author{
Marjorie A. Bowman, MD, MPA, and Anne Victoria Neale PhD, MPH
}

Starting with the Katerndahl et $\mathrm{al}^{1}$ article-family physician care is more complex per hour than that of cardiologists or psychiatrists. Whew! What an important statement, and what a difficult fact for our health system to believe and adequately support. This is discussed more fully in the related editorial. ${ }^{2}$ It is this same complexity of the human condition, and the interplay of these many factors in people's lives, that draws us to family medicine.

\section{Doctor Communication Influences Many Entities and Patient Experiences}

Doctor-patient communication influences many entities and patient experiences, including back pain, exercise counseling, preferences for depression treatment, prehypertension, and individual entities such as neurofibromatosis ${ }^{3}$ and Huntington disease. $^{4}$

Two articles in this issue use standard techniques for analysis of audio-recorded visits to study specific provider-patient communications. ${ }^{5,6}$ Both address common issues: exercise and low back pain. Patel and Parchman ${ }^{5}$ considered communication about exercise for patients with diabetes and found that discussions of exercise were significantly longer in offices with full implementation of the Chronic Care Model. There was also more discussion-and understandably so-when the patients were in the contemplation, preparation, or action stages of change.

Shaw et $\mathrm{al}^{6}$ found that we do not yet know the best doctor communication methods to prevent persistence of acute, work-related back pain. The work is informative and finds that the actual communication during the visits was not what would be suggested as potentially effective based on previous studies. The authors' suggestions for further interventions to be studied should be considered by clinicians now.

This article was not externally peer reviewed.

Conflict of interest: The authors are editors of JABFM.

\section{Depression Hurts}

Depression is persistently prevalent. We have made very little headway in the United States. Years after new medications, widely available (although not necessarily affordable) talk therapy, and more and more evidence that treatment helps, many people continue to suffer. ${ }^{7}$ It can be depressing just to think about the smallness of our success in the sea of symptoms and negative patient outcomes. Just how much does the psychosocial determinants of health override the potential health system answers to this common ailment? Fernandez y Garcia et al ${ }^{8}$ provide some insight with their investigation of the preferences for pharmacologic treatment of depression among Hispanics. In an important distinction, it was the lesser belief in biomedical explanations for depression that explained their lower preferences for drug treatment, not whether or not the interview was conducted in their native language (a potential measure of acculturation). That is, although it seemed that it was patients who were interviewed in Spanish who did not want medication, it was the underlying belief in the cause of depression that most determined the preferences for or against drug treatment. Biomedical explanation predicted acceptance of drug therapy. Thus, identifying patients' understanding of the underlying nature of depression can help us negotiate the most acceptable treatment.

\section{Research Letters}

Two research letters highlight misfortunes that can occur when overgeneralizations or lay beliefs are used to explain diseases. For example, remember the Elephant Man? Apparently many physicians and patients do, and they confuse his disease with neurofibromatosis. Please be careful using this analogy in practice because it is almost always incorrect and can suggest a much worse prognosis for patients with neurofibromatosis than is actually the case. Bouffard ${ }^{3}$ provides additional history and insight. In the other letter, the movements of Huntington disease can be interpreted as witchcraft, 
leading to unnecessary and potentially unfortunate delays in identification and treatment. ${ }^{4}$

In another research letter, Viera ${ }^{9}$ identified that patients are not being told that they have borderline or prehypertension. The value of this remains currently unclear, but hopefully physicians are identifying these patients and addressing appropriate lifestyle issues.

\section{Colorectal Cancer and Prevention Screening}

A recent article in the Fournal of the American Medical Association ${ }^{10}$ suggests that patients with advanced cancer receive too many preventive services. On the other hand, the article by Baldwin et $\mathrm{al}^{11}$ in this issue of our fournal finds that some colorectal cancer patients still don't receive enough preventive services. The difference is related to prognosis for the cancer and which types of preventive services are discussed.

A flu shot (as studied in the Baldwin ${ }^{11}$ article), for example, is appropriate for almost any patient with cancer at any stage. However, ongoing mammograms or colonoscopies would not make much sense for those with poor prognosis, eg, those with advanced pancreatic and lung cancer as discussed in the previously published Sima et $\mathrm{al}^{10}$ article. Further, Baldwin ${ }^{11}$ discusses a prospective study, which compares rates before and after; ie, not only did these patients receive some preventive services, the rate sometimes increased after diagnosis (perhaps because of contact with the health care system), but it still was often inadequate.

Short $^{12}$ provides us with data on 2 family physician colonoscopists at an Army hospital, showing good satisfaction with care while the procedures met all expected technical outcome measures. It is possible. There is nothing inherent about family physicians that would prevent them from such technical skills; it is more a matter of the appropriate up-front training, logistic practice support, and ongoing monitoring of outcomes.

\section{Impacts of Obesity on Women}

Kulie et $\mathrm{al}^{13}$ review the impacts of obesity on women. Though many of the effects of obesity are similar to those for men, there are relationships between obesity and women's medical problems that are often underappreciated. For example, obesity is associated with a 10 -fold increase in the rate of knee replacement, reflecting just how damaging excess weight is for the knee. Obesity can decrease the effectiveness of birth control, and the excess cervical cancer mortality is related to obese women's reluctance to get Papanicolaou smears; we need to remember to encourage women to get Papanicolaou smears in a nonjudgmental manner.

Pregnancy outcomes are worse, and breastfeeding is lower. Many of these poorer outcomes can have a long-term impact on the children and families of obese women. The data suggests that prevention of obesity is better in relationship to changing these outcomes than treatment of obesity once it has occurred. Much to ponder.

\section{Ibutilide for Atrial Fibrillation and Flutter}

Atrial fibrillation and flutter are very common; atrial fibrillation affects more than $5 \%$ of Americans over the age of $70 .{ }^{14}$ Even for those whose practice circumstances mean that ibutilide is a drug that they would not personally be administering, the sheer number of patients in family physician practices with atrial fibrillation means it is helpful to be aware of this drug and its place as an option for treatment. ${ }^{15}$

\section{Cheap, Safe, and Simple}

We love simple, cheap, safe, and effective treatments for chronic diseases that plague our patients. Vicks ${ }^{\circledR}$ VapoRub® for toenail fungus ${ }^{16}$ is simple, cheap, and safe. Is it effective? Although this study is a case series and a randomized controlled trial is indicated, the outcomes were as good as or better than other treatments reported in the literature. Given that toenail and foot fungus is associated with pain, local infections, and other complications (particularly for those with diabetes), we hope this treatment withstands the test of further study and use in practice.

\section{Getting There: Family Medicine into Low-Resource Settings}

A multistrategy intervention increased the number of students entering rural family medicine. ${ }^{17}$ Keys to success included student selection, family physician teachers, and a special preparation year before medical school.

Kollisch et $\mathrm{al}^{18}$ identified one method of improving health care, specifically primary care, in the low-income and war-devastated country of Kosovo. A number of US medical schools and family med- 
icine programs have worked to help develop family medicine throughout the world. This article provides an insight to one mechanism that has achieved success despite formidable obstacles.

\section{References}

1. Katerndahl D, Wood R, Jaén CR. Family medicine outpatient encounters are more complex than those of cardiology and psychiatry. J Am Board Fam Med 2011;24:6-15.

2. Bowman MA. The depth, breadth and complexity of family medicine care. J Am Board Fam Med 2011; 24:4-5.

3. Legendre CM, Charpentier-Côté C, Drouin R, Bouffard C. Neurofibromatosis type 1: persisting misidentification with "the Elephant Man" disease. J Am Board Fam Med 2011;24:112-114.

4. Penaranda E, Garcia A, Montgomery L. It wasn't witchcraft - it was Huntington disease! J Am Board Fam Med 2011;24:115-116.

5. Patel NK, Parchman ML. The Chronic Care Model and exercise discussions during primary care diabetes encounters. J Am Board Fam Med 2011;24:26-32.

6. Shaw WS, Pransky G, Roter DL, Winters T, Tveito TH, Larson SM. The effects of patient-provider communication on 3-month recovery from acute low back pain. J Am Board Fam Med 2011;24:16-25.

7. Shim R, Baltrus P, Ye J, Rust G. Prevalence, treatment, and control of depressive symptoms in the United States: results from the NHANES 20052008. J Am Board Fam Med 2011;24:33-38.

8. Fernandez y Garcia E, Franks P, Jerant A, Bell RA, Kravitz RL. Depression treatment preferences of Hispanic individuals: exploring the influence of ethnicity, language, and explanatory models. J Am Board Fam Med 2011;24:39-50.

9. Viera AJ, Bangura F, Mitchell CM, Cerna A, Sloane P. Do clinicians tell patients they have prehypertension? J Am Board Fam Med 2011;24:117-118.
10. Sima CS, Panageas KS, Schrag D. Cancer screening among patients with advanced cancer. JAMA 2010; 304:1584-91.

11. Baldwin LM, Dobie SA, Cai Y, Saver BG, Green PK, Wang CY. Receipt of general medical care by colorectal cancer patients: a longitudinal study. J Am Board Fam Med 2011;24:57-68.

12. Nijjar UK, Edwards JA, Short MW. Patient satisfaction with family physician colonoscopists. J Am Board Fam Med 2011;24:51-56.

13. Kulie T, Slattengren A, Redmer J, Counts H, Eglash A, Schrager S. Obesity and women's health: an evidence-based review. J Am Board Fam Med 2011;24: 75-85.

14. Fuster V, Rydén LE, Asinger RW, et al. ACC/AHA/ ESC guidelines for the management of patients with atrial fibrillation: a report of the American College of Cardiology/American Heart Association Task Force on Practice Guidelines and the European Society of Cardiology Committee for Practice Guidelines and Policy Conferences (Committee to Develop Guidelines for the Management of Patients with Atrial Fibrillation) developed in collaboration with the North American Society of Pacing and Electrophysiology. J Am Coll Cardiol 2001;38:1266.

15. Nair M, George LK, Santhosh KG, Koshy SKG. Safety and efficacy of ibutilide in cardioversion of atrial flutter and fibrillation. J Am Board Fam Med 2011;24:86-92.

16. Derby R, Rohal P, Jackson C, Beutler A, Olsen C. Novel treatment of onychomycosis using over-thecounter mentholated ointment: a clinical case series. J Am Board Fam Med 2011;24:69-74.

17. Wheat JR, Leeper JD, Brandon JE, Guin SM, Jackson JR. The rural medical scholars program study: data to inform rural health policy. J Am Board Fam Med 2011;24:93-101.

18. Kollisch DO, Hammond CS, Thompson E, Strickler J. Improving family medicine in Kosovo with microsystems. J Am Board Fam Med 2011;24:102-111. 